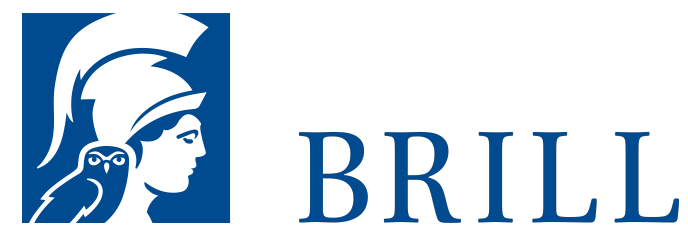

\title{
Verwaltung in Diktatur und Demokratie
}

Die Bezirksregierungen Münster und Minden/Detmold von 1930 bis 1960

Author: Hedwig Schrulle

In der ersten Hälfte des 2o. Jahrhunderts erlebte Deutschland drei radikale Umbrüche der staatlichen Ordnung, auf die die öffentliche Verwaltung mit größter Beharrungskraft reagierte, vor allem hinsichtlich ihrer organisatorischen und personalen Strukturen, während sie sich andererseits flexibel an die jeweiligen neuen Verhältnisse anpasste. Hedwig Schrulle geht am Beispiel der westfälischen Bezirksregierungen Münster und Minden/Detmold der Frage nach, welche Funktionen den behördlichen Apparaten im diktatorischen Machtstaat und im demokra-tischen Staat zugedacht waren und in welchem Umfang sie diesen nachkamen oder ihnen entgegenarbeiteten. Sie rekonstruiert und analysiert am Beispiel von Aufgabenfeldern wie Personalpolitik und Bau-, Schul- und Medizinalverwaltung das Handeln dieser Mittelinstanzen. Die Auto- rin zeigt, welchen Beitrag die Bezirksregierungen zur nationalsozialisti-schen Durchdringung der Gesellschaft leisteten und in welchem Ausmaß sie sich nach 1945 um eine personelle und 'ideelle' Entnazifizierung be-mühten.

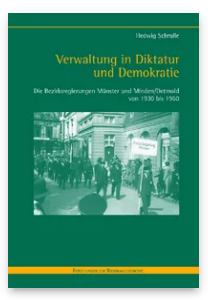

Pages: 765

Seiten

Language:

German

Subjects: Global

History, History

Publisher: Brill |

Schöningh

Series:

Forschungen zur Regionalgeschichte,

Volume: 6o

E-Book (PDF)

Released online:

29 Jan 2020

ISBN: $978-3^{-}$

657-76593-5

List price

USD $\$ 101.00$

Hardback

Publication date:

21 Jan 2009

ISBN: 978-3-

506-76593-2 
For more information see brill.com

Order information: Order online at brill.com +44330 333 0049 | customerservices@brill.com Submission information: brill.com/authors

Titles published by Brill | Fink, Brill | mentis or Brill | Schöningh: +49(o)715413279216| brill@brocom.de 